\title{
Developing Sports Physiotherapy Expertise - The Value of Informal Learning
}

\author{
Colin Paterson, MSc, PGCert (Ed), MCSP ${ }^{1}$, Nicola Phillips, OBE, PhD, FCSP ${ }^{2}$ \\ 1 University of Brighton, Eastbourne, United Kingdom, ${ }^{2}$ Cardiff University, Cardiff, United Kingdom \\ Keywords: education, mentorship, sports physiotherapy \\ https://doi.org/10.26603/001c.23608
}

\section{International Journal of Sports Physical Therapy}

Vol. 16, Issue 3, 2021

\section{INTRODUCTION}

Expertise, which can be developed through specialization in sports physiotherapy, has evolved as part of lifelong learning to improve patient care. ${ }^{1,2}$ Specialization is described as having in-depth knowledge, skills and competence in a specific area of practice. ${ }^{3}$ The International Federation of Sports Physical Therapy (IFSPT) provides a specialist recognition process through certification by member organisations, which includes masters level knowledge and skills mapped to competencies, while also demonstrating situational and contextual awareness. ${ }^{2}$ The process acknowledges and promotes that becoming a specialist involves more than merely successfully completing a course of study, rather, it requires a longer period of reflective practice in the sports physiotherapy field.

Typically, professional expertise is considered a gradual transition, often starting with formal (university) education and then specializing through (clinical) experience and ongoing informal learning, which builds upon this academic foundation. ${ }^{4}$ Experts in a specialized field demonstrate ongoing regular deliberate practice and consistently successful superior performance in complex situations. ${ }^{5}$ Not all specialists will become 'experts' but a suitable specialization process can facilitate developing expertise characteristics. In this international perspective the authors are encouraging the reader to consider how you are developing or maintaining your own, and others' level of expertise, which will in turn enhance the practice of sports physiotherapy.

The authors have previously proposed a model of expertise development in sports physiotherapy. ${ }^{6}$ Inthis model, learning is categorized into technical (scientific and skillbased), creative (adapting decision-making and techniques to clinical situation) and contextual (self-awareness and ability to adapt behaviors within wider cultural and situational circumstances). ${ }^{6}$ Creative and contextual learning both improve with informal practical/experiential learning. Novices typically have the technical knowledgeto support evidence-based practice but lack the depth of experience on which to base their practice decisions, especially in complex situations. ${ }^{7}$ Individuals then continue to critically appraise available evidence and reflect on patient outcomes to further modify their practice while on a specialist pathway. Sports related examples of different characteristics across novice to expert, to illustrate this, can be seen in Figure 1.

\section{LEARNING, REFLECTION AND KNOWLEDGE}

Formal learning is typically planned, 'teacher' led and explicit, while informal learning is usually unplanned, experiential, reactive and implicit in nature. ${ }^{8}$ Physiotherapists use both, with the limited available evidence suggesting that they seem to prefer formal learning, but it is not clear why. ${ }^{9}$ In contrast to these preferences, learning has been shown to be more effective when it happens in a supportive learning community and within practice environments, which suggests more implicit learning. ${ }^{8}$

Developing this implicit learning style enhances skill retention and the ability to transfer to novel circumstances but it can take longerinitially. ${ }^{10}$ The authors feel that this time constraint may be why busy practitioners typically prefer explicit learning opportunities when asked about preferred methods of learning. Not all experiences trigger the same amount of reflection with expected outcomes tending to confirm existing knowledge, thereby triggering less reflection than an unexpected outcome where reflection generates new learning and knowledge. ${ }^{2,4,8}$ As reflection encourages creative and contextual learning, the authors suggest that a deliberate strategy to encourage evidencing reflective practice would address the perceived value of informal implicit learning. Experience alone does not appear to be enough to generate expertise, rather the development of expertise depends on the nature and frequency of reflection. Being able to question areas of practice while being exposed to different ways of thinking within a community of practice takes commitment to accruing both experience and feedback. ${ }^{3}$ The authors suggest that a strategy to encourage developing practitioners to more readily share unexpected, potentially suboptimal outcomes, would more effectively facilitate learning, but this requires a change in attitudes.

\section{SUMMARY}

It is clear that expertise is more than isolated formal learning and requires additional deliberate practice and informal learning. From the authors' experiences, the challenge of using deliberate practice is to balance the need for mistakes to happen to facilitate implicit learning through reflection and problem solving, while attending to athlete safety. This is where mentoring and supervision becomes so important, especially in the competitive world of sport, where 


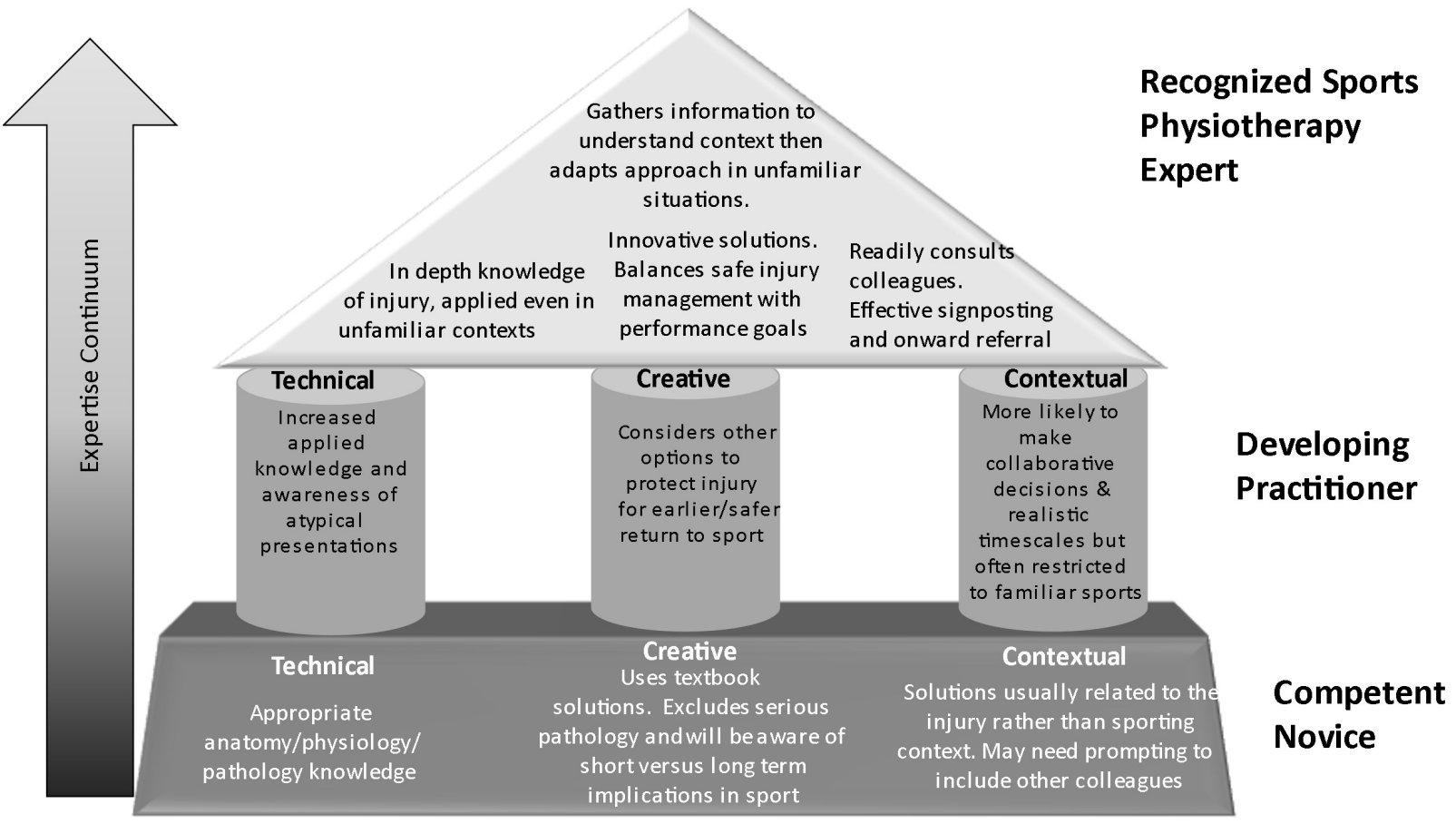

Figure 1: Example Sports Physiotherapy Characteristics Across Novice to Expert

performance is key and there is often little tolerance for errors. Thus, working with colleagues who possess greater expertise provides an element of protection to both the developing practitioner and the athlete. The specialist workforce scarcity and budget limitations mean that sports teams will readily recruit novice practitioners, who often find themselves in a sole practitioner role very early in their careers. As a profession sports physiotherapy needs to develop a more effective community of practice, so that a platform can be created for future specialists to develop their expertise. This can be done virtually as well as through direct su- pervision butmust reflect the local cultural and economic environments in order to be effective.Easily accessible mentoring also helps keep the athlete safe, as well as benefiting both the mentor and mentee. The IFSPT and National member organizations can play an important role in changing attitudes towards using deliberate practice and presenting reflections on informal learning to include a breadth of experiences, both positive and negative.

Submitted: April 01, 2021 CDT, Accepted: May 01, 2021 CDT 


\section{REFERENCES}

1. Phillips N. Postgraduate specialisation in sports physiotherapy - Academic or clinical expertise? Phys Ther Sport. 2009;10(3):83. doi:10.1016/j.ptsp.2009.0 $\underline{5.003}$

2. IFSPT. www.ifspt.org. Accessed January 22, 2021.

3. Tawiah AK, Desmeules F, Wieler M, et al. Advanced practice in physiotherapy: A Global Survey.

Physiotherapy. February 2021. doi:10.1016/j.physio.20 21.01.001

4. Paterson C, Chapman J. Enhancing skills of critical reflection to evidence learning in professional practice. Phys Ther Sport. 2013;14(3):133-138. doi:1 0.1016/i.ptsp.2013.03.004

5. Ericsson KA, Prietula MJ, Cokely ET. The making of an expert. Harv Bus Rev. 2007;85(7-8):115-121.

6. Phillips N, Paterson C. Growing sports physiotherapy experts takes a village-technical, creative and contextual learning doesn't happen in a vacuum. Br J Sports Med. 2020;54(9):498-503. doi:10.1 136/bjsports-2019-101333
7. Phillips N, Grant M-E, Booth L, Glasgow P. Using criteria-based interview models for assessing clinical expertise to select physiotherapists at major multisport games. Br J Sports Med. 2015;49(5):312-317. doi:10.1136/bjsports-2014-09417 $\underline{6}$

8. Merriam SB, Baumgartner LM. Learning in Adulthood. A Comprehensive Guide. 4th ed. New Jersey: Jossey-Bass; 2020.

9. French HP, Dowds F. An overview of continuing professional development in physiotherapy. Physiotherapy. 2008;94(3):190-197. doi:10.1016/i.phys io.2007.09.004

10. Masters RSW, Poolton JM, Maxwell JP, Raab M. Implicit motor learning and complex decision making in time-constrained environments. J Mot Behav. 2008;40(1):71-79. doi:10.3200/imbr.40.1.71-80 